\title{
Effect of deflector angle on hydrodynamic performances of a double- slotted cambered otter-board
}

\author{
Lei WANG, Lu Min WANG, Jian Gao SHI, Yu ZHANG, Yong Li LIU, Wen Wen YU, Xun ZHANGa \\ Key Laboratory of Oceanic and Polar Fisheries, Ministry of Agriculture; East China Sea Fisheries Research Institute, Chinese Academy of \\ Fishery Sciences, Shanghai 200090, China
}

\begin{abstract}
The effect of deflector angle on hydrodynamic performances of a double-slotted cambered otter-board is investigated using engineering models in a wind tunnel. Three different angle combinations $\left(35^{\circ}-30^{\circ}, 30^{\circ}-25^{\circ}\right.$ and $25^{\circ}$ $20^{\circ}$ ) are evaluated at a wind speed of $28 \mathrm{~m} / \mathrm{s}$. Parameters measured included: drag coefficient $\mathrm{C}_{\mathrm{x}}$, lift coefficient $\mathrm{C}_{\mathrm{y}}$, pitch moment coefficient $C_{m}$, center of pressure coefficient $C_{p}$, over a range of angle of attack $\left(0^{\circ}\right.$ to $\left.70^{\circ}\right)$. These coefficients are used in analyzing the differences in the performance among the three otter-board models. Results shows that the maximum lift coefficient $\mathrm{C}_{\mathrm{y}}$ of the otter-board model with the angle combination $\left(35^{\circ}-30^{\circ}\right)$ of two deflectors is the highest $\left(2.160\right.$ at $\left.\alpha=55^{\circ}\right)$. The maximum $\mathrm{C}_{\mathrm{y}} / \mathrm{C}_{\mathrm{x}}$ of the otter-board with the angle combination $\left(25^{\circ}-20^{\circ}\right)$ is the highest (3.842 at $\alpha=2.5^{\circ}$ ). A comparative analysis of $C_{m}$ and $C_{p}$ shows that the stability of otter-board model with the angle combination $\left(25^{\circ}-20^{\circ}\right)$ is better in pitch, and the stability of otter-board model with the angle combination $\left(30^{\circ}-25^{\circ}\right)$ is better in roll. The findings of this study can offer useful reference data for the structural optimization of otter-boards for trawling.
\end{abstract}

\section{Introduction}

Trawl doors are an important part of fishing gear for the spreading of a trawl. The merits of the hydrodynamic performance of otter-boards can be measured on the basis of the lift coefficient of the trawl door, the drag coefficient of the trawl door, and the pitching moment coefficient of the trawl door [1]. Optimizing the structure of otter-boards may improve the hydrodynamic performance of the otterboard and reduce the energy consumption of fishing vessels [2-3]. Extensive studies on the hydrodynamic performance of otter-boards have been conducted in the United States, Japan, Norway, and other countries [4-9]. In China, researchers have studied the relevant hydrodynamic performance of otter-boards since the early 1980s, including the hydrodynamic performance and optimization of different otter-boards with various structure types. The development of offshore trawler fleets has increased globally in recent decades, raising the demand for improved otter-board designs. Accordingly, improvements in the hydrodynamic performance of otter-boards has become a major research interest. Some studies have shown that the slit in otter-boards can reduce the resistance and improve the stability of otter-boards [10-15]. The following study investigates the importance of the angle of the deflector within the otter-board. We describe an experiment using model otter-boards ( $n=3$ designs $)$ in a wind tunnel in which we measured various hydrodynamic coefficients for a range of angles of attack. The results are relevant as a reference for the study of the structural parameters of the main-panel of otter-boards.

\section{Material and Methods}

\subsection{Design and manufacture of otter-board model}

The otter-boards evaluated in this study are double-slit curved structures comprising two deflectors and one mainpanel (figure 1). This simplified design is selected in order to meet objectives and requirements of the study. Only the angle of two deflectors are modified.

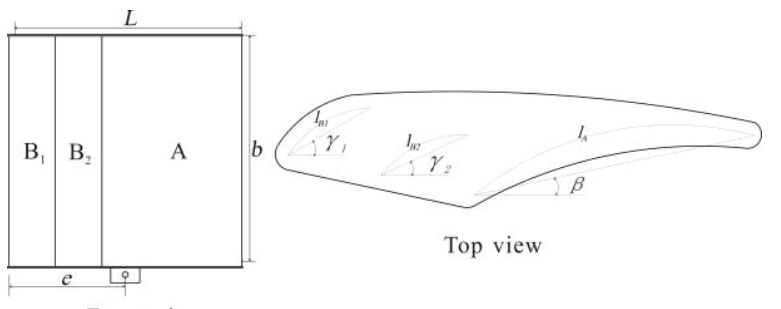

Front view

Figure 1 Structure and parameters of otter-board

Note: $L$ : chord; $b$ : span; $e$ : distance between fulcrum and the front end of model; $\mathrm{B}_{1}, \mathrm{~B}_{2}$ : deflector; A: main-panel; $\gamma_{1}$, $\gamma_{2}$ : angle of deflector; $\beta$ : angle of main-panel; $l_{B 1}, l_{B 2}$ : arc length of deflector; $l_{A}$ : arc length of main-panel

Each of models has an aspect ratio of 1.0, surface area of $0.25 \mathrm{~m}^{2}$, and are identical in many structural parameters and dimensions (table 1). The curvature of the deflector

\footnotetext{
a Corresponding author: zhangxun007@hotmail.com
} 
and main panels is $12 \%$ and is consistent in all models. The only parameter that varied between the models is the angle of two deflectors $\left(\gamma_{1}, \gamma_{2}\right)$. The models are made of steel with painted surfaces (figure 2).

\begin{tabular}{ccccccccccccc}
\multicolumn{1}{c}{ Table 1 Descriptive characteristics of the three model otter boards evaluated in this stud } \\
\hline No. & $L / \mathrm{m}$ & $b / \mathrm{m}$ & $\lambda$ & $S / \mathrm{m}^{2}$ & $e / \mathrm{m}$ & $\gamma_{1}$ & $\gamma_{2}$ & $\beta$ & $l_{B 1}$ & $l_{B 2}$ & $l_{A}$ \\
\hline 1 & 0.50 & 0.50 & 1.0 & 0.25 & 0.25 & $35^{\circ}$ & $30^{\circ}$ & $6^{\circ}$ & 0.127 & 0.120 & 0.313 \\
2 & 0.50 & 0.50 & 1.0 & 0.25 & 0.25 & $30^{\circ}$ & $25^{\circ}$ & $6^{\circ}$ & 0.127 & 0.120 & 0.313 \\
3 & 0.50 & 0.50 & 1.0 & 0.25 & 0.25 & $25^{\circ}$ & $20^{\circ}$ & $6^{\circ}$ & 0.127 & 0.120 & 0.313 \\
\hline
\end{tabular}

Note: $L$ : chord; $b$ : span; $\lambda$ : aspect ratio $(b / L) ; S$ : surface area $(L \cdot b)$; e: distance between fulcrum and the front end of model; $\gamma_{1}, \gamma_{2}$ : angle of deflector; $\beta$ : angle of main-panel; $l_{B 1}, l_{B 2}$ : arc length of deflector; $l_{A}$ : arc length of main-panel.
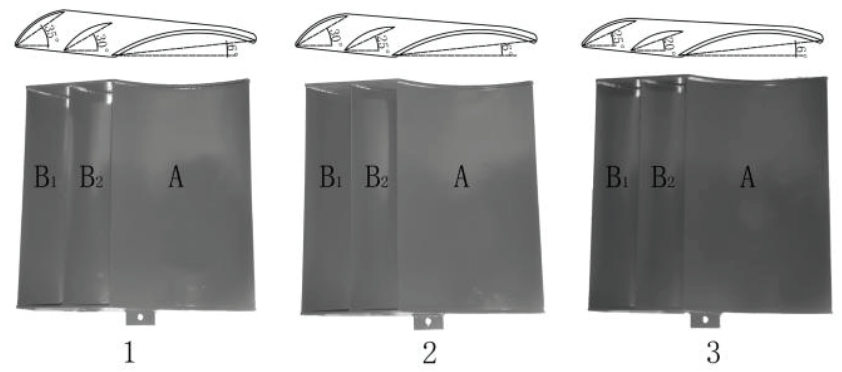

Note: A: main-panel; $\mathrm{B}_{1}, \mathrm{~B}_{2}$ : deflector.

Figure 2 Three otter-board models evaluated in this study.

\subsection{Test facility}

The wind tunnel used for this experiment is the NH-2 wind tunnel located at Nanjing University of Aeronautics and Astronautics, China. The tunnel is a closed reflux wind tunnel with a double-string test section. The experiment is conducted in a small test section. Dimensions of the test section are $6 \mathrm{~m}$ (length) $\times 3 \mathrm{~m}$ (width) $\times 2.5 \mathrm{~m}$ (height) The cross-sectional area is $7.18 \mathrm{~m}^{2}$. The minimum and maximum wind speeds of the tunnel are $5 \mathrm{~m} / \mathrm{s}$ and $90 \mathrm{~m} / \mathrm{s}$, respectively. Figure 3 illustrates the experimental setup inside the wind tunnel. The model otter-boards are attached to a dynamometer compromising a six-component mechanical tower-balance to measure forces in all directions. The data acquisition and processing system used is composed of a pre -amplifier and a four -networked computer system.

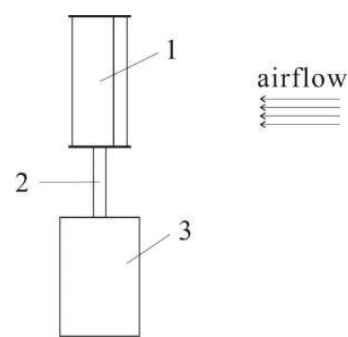

Figure 3 Installation instruction of otter-board model in wind tunnel

Note: 1. otter-board model 2 .model connection 3.sixcomponent force balance

\subsection{Test method}

\subsubsection{Parameter definition of test model}

Test models need to be installed on the wind tunnel in six- component balance mechanical base according to the order, angle of attack of model rotates by the $0^{\circ}-70^{\circ}$ when the wind speed reaches $28 \mathrm{~m} / \mathrm{s}$ (room temperature $20{ }^{\circ} \mathrm{C}$ ), wherein the angle of attack in the range $0^{\circ}-50^{\circ}$, $2.5^{\circ}$ intervals to record a measurement data point, after the attack angle $50^{\circ}$, each measurement interval of $5^{\circ}$ to record data points, there are 25 sets of data totally, including the drag coefficient $C_{x}$, the lift coefficient $C_{y}$, the pitch moment coefficient $C_{\mathrm{m}}$ and the center of pressure coefficient $C_{\mathrm{p}}$.

The relevant parameters of models in the wind tunnel test section are defined as shown in figure 4. In figure $4, \mathrm{O}$ is torque reference point, which is the punch of the model at the bottom. During the test, the resistance of the model is provided by the force of balance along the $\mathrm{X}$-axis direction, the lift is provided by the force of balance along the $\mathrm{Z}$-axis direction, and the pitch moment is provided by the $M_{\mathrm{y}}$ of balance along the $\mathrm{Z}$-axis direction.

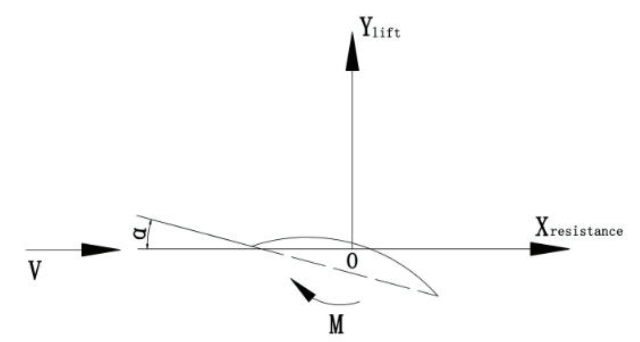

Figure 4 Parameter definition diagram of test model in wind tunnel

For this test, Wind speed $V=28 \mathrm{~m} / \mathrm{s}$, when the Reynolds number $R_{e}=V L / v=0.93 \times 10^{6} \quad$ (coefficient of viscosity $\left.v=15 \times 10^{6} \mathrm{~m}^{2} \cdot \mathrm{s}^{-1}\right)[10]$.

\subsubsection{Parameter definition of test measurement}


Three components: lift $Y$, drag $X$, pitching moment $M$ (around the fulcrum), while the distance from the center of pressure to the front-end otter-board $d=e-(M / N)$ [12], $(N$ is the normal force).

Lift coefficient $C_{y}=\frac{Y}{\rho V^{2} S / 2}[3]$; drag coefficient $C_{x}=\frac{X}{\rho V^{2} S / 2} ;$ pitch moment coefficient ${ }_{C_{m}}=\frac{M}{\rho V^{2} S L / 2} ;$ center of pressure coefficient $C_{p}=\frac{d}{L}$.

Air density $\rho=1.225 \mathrm{~kg} / \mathrm{m}^{3}$ in above formula; $S$ is otterboard area $\left(\mathrm{m}^{2}\right) ; L$ is the otter-board chord length $(\mathrm{m})$.

All the experimental data have been carried out the stent disturbance correction which is completed by the method of taking out light pole directly.

\subsection{Drag coefficient and lift coefficient}

Data from the experiment includes the drag coefficient $C_{x}$, the lift coefficient $C_{y}$, the pitch moment coefficient $C_{\mathrm{m}}$, and the center of pressure coefficient $C_{p}$. The lift-drag ratio is computed $\left(C_{y} / C_{x}\right)$, which is an important factor for determining the merits of the hydrodynamic performance of otter-boards. An otter-board with excellent hydrodynamic properties can achieve higher lift-drag ratio and improved stability; such performance can be analyzed by comparing the pitching moment coefficient $C_{\mathrm{m}}$ stencil and the center of pressure coefficient $C_{p}$. The test data are divided into groups, yielding $C_{x}-\alpha, C_{y}-\alpha$ and $C_{y} / C_{x}-\alpha$ graphs shown in figure 5. These graphs are used for analyzing the differences in the hydrodynamic properties of the three otter-board models.

\section{Results and Discussion}

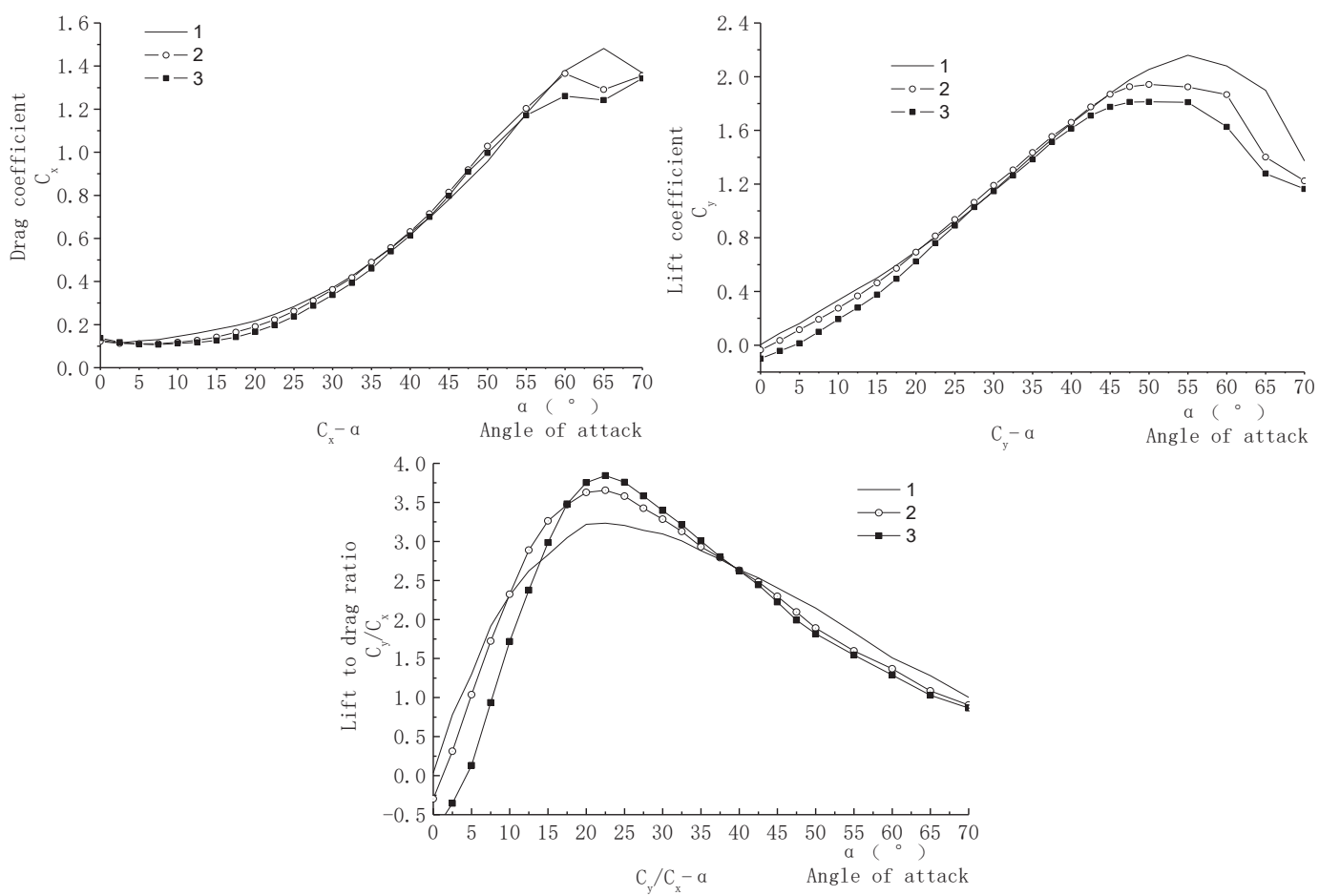

Figure 5 Hydrodynamic properties of three otter-board models across a range of angle of attack

In figure $5, C_{x}-\alpha$ and $C_{y}-\alpha$ graphs show the variation curve of the drag and lift coefficient of the three models while the angle of attack $\alpha$ changes. The relationship between $C_{x}$ and $\alpha$ is proportional totally. The maximum lift coefficients $C_{y}$ of No. 1, No. 2, and No. 3 otter-board models are $2.160\left(\alpha=55^{\circ}\right), 1.942\left(\alpha=50^{\circ}\right)$, and $1.812(\alpha$ $\left.=50^{\circ}\right)$, respectively. It shows that the maximum lift coefficients becomes larger as the angle of two deflectors increasing.

\subsection{Lift-drag ratio}

In figure 5, the maximum lift-drag ratios of No.3 model with a small angle of two deflectors is $3.842\left(\alpha=22.5^{\circ}\right)$, and the maximum lift-drag ratios of No. 1 and No. 2 models are $3.234\left(\alpha=22.5^{\circ}\right)$ and $3.655\left(\alpha=22.5^{\circ}\right)$, respectively. The increasing of two deflectors' angle may result in a lower maximum lift-drag ratio.

\subsection{Stability of otter-board}

Pitching moment can be divided into upper and lower pitching moments, what are usually distinguished by positive and negative values, Positive means the otterboard tilts backward, and negative means tilts forward. Its absolute value represents the level of pitching moment; and the pitching moment coefficient tending to zero represents the more excellent stability of otter-board. In practice, comparing the absolute value $C_{m}$ corresponding to the operation angle of attack of otter-board may determine the stability level of otter-board. For comparison, the angle of attack corresponding to the maximum lift-drag ratio $C_{\mathrm{y}} / C_{\mathrm{x}}$ 
is selected [16]. The corresponding absolute value of $C_{m}$ is shown in table 2. The absolute value of $C_{m}$ of No. 3 model is 0.144 , so hence, the stability of No. 3 otter-board model is better in pitch.

Table 2 Parameters of three otter-board for stability analysis

\begin{tabular}{|c|c|c|c|}
\hline No. & $\begin{array}{c}\text { Angle } \\
\text { corresponding to } \\
\text { the maximum lift } \\
\text {-drag ratio } \\
\alpha \\
\end{array}$ & $\left|C_{\mathrm{m}}\right|$ & $\begin{array}{c}\text { Variable } \\
\text { coefficient of } \\
C_{\mathrm{p}}\end{array}$ \\
\hline 1 & $22.5^{\circ}$ & 0.287 & $10.12 \%$ \\
\hline 2 & $22.5^{\circ}$ & 0.180 & $5.49 \%$ \\
\hline 3 & $22.5^{\circ}$ & 0.144 & $8.13 \%$ \\
\hline
\end{tabular}

The stability in roll of otter-board can be measured according to the center of pressure coefficient $C_{\mathrm{p}}$; and the way of comparison is analyzing the coefficient of variation in $C_{\mathrm{p}}$ within the range of angle approximately $5^{\circ}$ of the angle of attack corresponding to the maximum lift-drag ratio; a smaller coefficient results in the improved stability [17]. The calculated data is shown in table 2 . The minimum variation coefficient of $C_{\mathrm{p}}$ is $5.49 \%$; this value also means that the stability of No. 2 otter-board model is better in roll of otter-board.

\section{Conclusion}

Test analysis shows that the angle combination of two deflectors has a point for equilibrating the hydrodynamic performances of otter-board, results from this experiment suggest that a better angle combination of two deflectors should be $30^{\circ}$ and $25^{\circ}$, thereby yielding has a higher lift coefficient and higher lift-drag ratio on average, and the stability in roll and pitch of otter-board is also better comparatively. The data and conclusions of this study can provide a reference for the design of otter-board.

\section{Acknowledgements}

This work is financially supported by the National Key Technology R\&D Program (No. 2013BAD13B05).

\section{References}

1. Guo G X, Liu TY, Huang X H, Gu F L. Theory and Practice of trawl doors Kinetic [M]. Guangdong Science and Technology Publications, 2008.

2. Zhou Y Q. Mechanics of fishing gear [M]. China Agriculture Publications, 2001.

3. Chen X Z, Huang X C. Theory and method of gear model test $[\mathrm{M}]$. Shanghai Science and Technology Publications, 2011.

4. Sala A, Prat J, Antonijuan J, Lucchetti A. Performance and impact on the seabed of an existingand an experimental-otter board: Comparison between model testing and full-scale sea trials [J]. Fisheries Research, 2009, 100(2): 156-166.

5. Takahashi Y, Fujimori Y, Hu F X, Shen X L, Kimura N. Design of trawl otter boards using computational fluid dynamics [J]. Fisheries Research, 2015, 161:
400-407.

6. Shen X L, Hu F X, Kumazawa T, Shiode D, Tokai T. Hydrodynamic characteristics of a hyper-lift otter board with wing-end plates $[\mathrm{J}]$. Fisheries Science, 2015, 81(3): 433-442.

7. Broadhurst M K, Sterling D J, Millar R B. Modifying otter boards to reduce bottom contact: Effects on catches and efficiencies of triple-rigged penaeid trawls [J]. Fisheries Management and Ecology, 2015, 22(5): 407-418.

8. Fukuda K, Hu F X, Tokai T, Matuda K. Effect of Aspect Ratio on Lift and Drag Coefficients of Cambered Plates [J]. Nippon Suisan Gakkaishi, 2000, 66(1): 97-103.

9. Park C D, Matuda K, Hu F X. Effects of Dihedral and Sweepback Angles on Lift and Drag of the Cambered Otter Board [J]. Nippon Suisan Gakkaishi, 1996, 62(6): 920-927.

10. Zhang X, Wang J H, Wang M Y, Yu Y F, Xu, B. S. Hydrodynamic characteristics of rectangular cambered V type otter board-- I : Relationship between cambered ratio of fairwater fin and hydrodynamic characteristics of otter board [J]. Journal of Fishery Sciences of China, 2004, 11(z1): 5-8.

11. Wang J H, Wang M Y, Zhang X, Yu Y F, Xu B S. Hydrodynamic characteristics of rectangular cambered V type otter board-- II : Effects of aspect ratio, slotted position and slotted width on hydrodynamic characteristics of otter board [J]. Journal of Fishery Sciences of China, 2004, S1: 9-13.

12. Wang M Y, Wang J H, Zhang X, Yu Y F, Xu B S. Hydrodynamic characteristics of vertical $\mathrm{V}$ type otter board [J]. Journal of Fisheries of China, 2004, 3: 311 315.

13. Li C C, Liang Z L, Huang L Y, Zhou W F, Sun P, Wang L. Hydrodynamic study on a vee type otter board of small trawl vessels [J]. Marine Sciences, 2013, 11: 69-73.

14. Wang L, Wang L M, Feng C L, Zhang X, Shi J G, Zhang Y, Liu Y L, Yu W W. Influence of vane dimension on hydrodynamic performances of single slotted cambered otter board [J]. Fishery Modernization, 2015, 6: 55-60.

15. Wang L, Wang L M, Yu W W, Feng C L, Shi J G, Liu $\mathrm{Y} \mathrm{L}$, Zhang $\mathrm{X}$. Influence of deflector angular variation on hydrodynamic performances of single slotted cambered otter board [C]. Conference: International Forum on Energy, Environment and Sustainable Development, 2016, 75: 530-535.

16. Yang L. Hydrodynamic characteristics of slotted circular plate $[\mathrm{J}]$. Fisheries Science and Technology, 1996, 2: 38-41.

17. Yang L. Hydrodynamic characteristics of double plate circular plate $[\mathrm{J}]$. Fisheries Science and Technology, 1996, 5: 42-44. 